DOI: https://doi.org/10.15688/lc.jvolsu.2017.2.13

UDC 347.457 .1

LBC 65.272.21

\title{
BANKNOTE AS A PAYMENT BANK SECURITY
}

\author{
Alexander I. Goncharov \\ Volgograd Institute of Management - RANEPA Branch, Volgograd, Russian Federation
}

\begin{abstract}
Introduction: the banknote is a security, mediating the fulfillment of an obligation (the transfer of goods, the performance of works, the provision of services, the provision of property rights, the enjoyment of intellectual property rights) carried out as counter, in the process of payment and delivery of the banknote which is presented to the other party of the settlement by a holder. The transferability of the banknote is absolute; it is the cash that reflects the higher degree of liquidity of any asset. However, the banknote exists on the basis of trust which is guaranteed by the lender of the last resort - the Central Bank of a state. The purpose of the study is to reveal the legal status of the banknote as a payment bank security. Methods: there have been applied in conjunction the methods of scientific knowledge, among which the basic are the methods of historicism, systematicity, analysis and the comparative law method. Results: it is proved that the banknote as a currency unit, issued and guaranteed by the Central Bank, allows you to efficiently and quickly produce a lot of cash payments in the economy. A person becomes the holder of banknotes in the result of payment for any public duties or private law monetary obligations. As time goes on, for the banknote you can get (buy) wealth less than a year and more ago. The state represented by the Central Bank of the country will participate and fully determine the future of the banknote as a bearer security. The banknote holds a deeply specific position among other securities. Conclusions: money in the form of sheets of paper (paper money) appeared in connection with the obstruction of metal currency as substitutes for silver and gold coins. In the Russian Empire paper money began to be used since 1769. In the Russian Federation banknotes are produced (emitted) by the Bank of Russia. The inflation process leads to continuous depreciation of the circulating banknotes. The banknote as a means of payment is not an investment tool and legal means of generating income as a result of the economic growth of the issuer. Behind the banknote there is the state in the person of its Central Bank with its entire guarantee, security and coercive power.
\end{abstract}

Key words: real money, tokens of value, paper money, banknote, payments, state, the Central Bank, trust.

УДК 347.457 .1

ББК 65.272 .21

\section{БАНКНОТА КАК РАСЧЕТНАЯ БАНКОВСКАЯ ЦЕННАЯ БУМАГА}

\author{
Александр Иванович Гончаров \\ Волгоградский институт управления - филиал РАНХиГС, \\ г. Волгоград, Российская Федерация
}

Введение: банкнота является ценной бумагой, опосредующей исполнение обязательства (передача товара, выполнение работ, оказание услуг, предоставление имущественных прав, реализация интеллектуальных прав), осуществляемого встречно, в процессе расчета и вручения банкноты, которая держателем предъявляется другой стороне расчета. Оборотоспособность банкноты абсолютна, именно наличные деньги отражают высшую степень ликвидности любого актива. Вместе с тем банкнота существует на фундаменте дове구의, которое гарантирует кредитор последней инстанции - центральный банк государства. Цель исследования - раскрыть правовое положение банкноты как расчетной банковской ценной бумаги. Методы: применены в совокупности методы научного познания, среди которых основные - методы историзма, системности, : анализа и сравнительно-правовой. Результаты: обосновано, что банкнота как денежный знак, выпускаемый в обращение и гарантируемый центральным банком, позволяет рационально и быстро производить массу శ (?) публичным обязанностям или частноправовым денежным обязательствам. С течением времени за банкно- 
ту можно получить (купить) материальных благ меньше, чем год и более назад. Государство в лице центрального банка страны обязательно участвует и полностью определяет судьбу банкноты как предъявительской ценной бумаги. Банкнота занимает в ряду ценных бумаг глубоко специфичное положение. Выводы: деньги в форме листков бумаги (бумажные деньги) появились в связи с затруднением металлического денежного обращения как заместители серебряных и золотых монет. В Российской империи бумажные деньги начали применяться с 1769 года. Банкноты в Российской Федерации выпускает (эмитирует) Банк России. Инфляционный процесс обусловливает непрерывное обесценивание обращающихся банкнот. Банкнота, будучи платежным средством, не является инвестиционным инструментом и юридическим средством получения дохода в результате экономического роста эмитента. За банкнотой всей своей гарантийной, обеспечительной и принудительной мощью стоит государство в лице своего центрального банка.

Ключевые слова: действительные деньги, знаки стоимости, бумажные деньги, банкнота, расчеты, государство, центральный банк, доверие.

\section{Введение}

Ценные бумаги мы исследуем в трехлетнем цикле статей нашего журнала. Первоначально рассматривались инструменты, инвестиционные вложения в которые влекут за собой формирование вещно-правовой связи инвестора с коммерческой организацией, получающей такие вложения. Затем мы обратили внимание на так называемые долговые ценные бумаги, они вполне оборотоспособны и представляют предпринимательский интерес как для коллективного, так и для индивидуального инвестора. Далее мы перешли к расчетно-кредитным и торговым ценным бумагам. Банкнота и чек по длительности применения в обороте следуют за векселем, располагаясь соответственно на втором и третьем местах. Специальным субъектом и обязательным участником расчетов, которые осуществляются посредством этих ценных бумаг, является банк.

\section{Банкнота как продукт эволюции и юридический заменитель денег}

Банкнота стала общепризнанной предъявительской ценной бумагой в результате довольно длительной эволюции денег. Деньги существуют многие сотни лет и, постоянно изменяясь, проходят определенные этапы развития, отражающие смену форм стоимости, этот процесс продолжается и в настоящее время. Издавна, помимо воли людей, некоторые изделия выделялись из товарного разнообразия и в дальнейшем занимали при обмене особое положение. На роль денег долгое время пробовались различные товары, но самыми подходящими оказались драгоценные металлы - золото и серебро. В процессе эволюции денег сформировались два явно различимых их вида: действительные деньги и знаки стоимости (заместители или представители действительных денег).

Действительные деньги - это деньги, номинальная стоимость которых обозначена на них, причем эта стоимость соответствует действительной стоимости металла, из которого деньги изготовлены. Деньги в форме монеты (медной, серебряной, золотой, платиновой) первоначально чеканились произвольного вида, позднее - в соответствии с характерными чертами, утвержденными государством. Более удобной и оборотоспособной оказалась круглая форма монеты, потому что так она меньше стиралась.

В Киевской Руси чеканка монет началась в IX-X веках. Первоначально функционировали одновременно златники (золотые монеты) и сребреники (серебряные монеты). Во второй половине XIX в. несколько государств установили золотой стандарт. Главным из этих государств была Англия, которая вместе со своими доминионами, протекторатами и колониями занимала первое место в мире по золотодобыче. Перевод денежного оборота на металлический стандарт, в частности на золотой, обусловлен наличием у этого металла характеристик, превращающих его в самый подходящий товар для исполнения функций денег. В период золотомонетного стандарта основная денежная единица государства чеканилась в полноценной золотой монете, номинал которой соответствовал ценности затраченного на нее золота. В то время имел место свободный обмен бумажных знаков банкнот на золотые монеты. Серебряные и медные деньги служили для размена золотых. 
В этом случае ценность (стоимость) содержащегося в них металла, как правило, также была соизмерима с золотом.

C конца XIX в. - в начале XX в. с появлением крупного машинного производства проявился дисбаланс между значительно увеличившимися объемами производимых товаров и объемом денег в обращении. Реально имевшегося в наличии золота в соответствии с золотым стандартом стало не хватать для обеспечения товарооборота. Кроме того, к началу Первой мировой войны большинство государств для образования золотых запасов на случай войны изъяли из оборота деньги из драгоценных металлов. Их место заняли не обеспеченные золотом «заместители».

Знаки стоимости (заместители действительных денег) - это деньги, номинал которых многократно выше фактической стоимости их изготовления. Существует несколько заместителей действительных денег. Металлические знаки стоимости использовались в форме стершихся и специально обрезанных (распиленных) серебряных и золотых монет. В настоящее время применяется билонная монета - деньги с низкими номиналами («мелочь»), сделанные из сплавов меди, алюминия, никеля. Бумажные знаки стоимости используются в форме бумажных и кредитных денег. У заместителей действительных денег, в отличие от золота, собственная ценность на рынках была очень низкая. Знаки стоимости только подтверждали право их владельца обменять на них соответствующую стоимость. Вход в оборот заместителей действительных денег при золотом стандарте обусловлен объективной потребностью хозяйства: во-первых, объемы добычи золота отставали от масштабов товарооборота и не соответствовали количеству денег, необходимому для его обеспечения; во-вторых, обеспечение мелкого товарооборота золотыми монетами было невозможно.

Деньги в форме листков бумаги (бумажные деньги) - это знаки стоимости, представители действительных денег. Они появились в связи с затруднением металлического денежного обращения и начали функционировать как заместители серебряных и золотых денег. Первые бумажные деньги появились в Китае примерно девять веков назад, в Европе и Америке - в XVII-XVIII вв., в Российской империи они начали применяться с 1769 года. В настоящее время бумажные деньги исключительно редко обмениваются на золото. Выпускает (эмитирует) бумажные деньги государственное казначейство или центральный банк. Казначейство может использовать эмиссию бумажных денег непосредственно на государственные расходы, либо центральный банк выпускает бумажные деньги (банкноты) и кредитует ими правительство страны.

Бумажные деньги характеризуются неустойчивостью и быстро обесцениваются, со временем на одни и те же суммы можно купить все меньше товаров. Их неустойчивость определяется тем, что эмиссия бумажных денег связана прежде всего с нуждами государства, а не с потребностями товарооборота в деньгах. В рамках золотомонетного стандарта при избытке золотых монет они выводились из оборота в сокровища, при недостатке денег золото возвращалось в сферу денежного обращения.

При неизменной или уменьшающейся потребности товарооборота в деньгах нуждаемость у государства в деньгах может возрастать по разным причинам. В ряде случаев обесценение бумажных денег проявляется при пассивном платежном балансе страны, когда из заграницы получено платежей меньше, чем уплачено за рубеж, а также при падении курса национальной денежной единицы к валютам, в которых ведутся зарубежные платежи. В таких случаях бумажные деньги не могут накапливаться в качестве сокровищ.

Современная денежная система любой страны с рыночной экономикой интегрирует комплекс взаимосвязанных и взаимодействующих элементов. В их числе: 1) денежная единица как единица счета, необходимая для соизмерения цен товаров; 2) масштаб цен; 3) виды обращающихся денежных знаков, представляющих собой законные платежные средства; 4) эмиссионный и гарантийный механизм для выпускаемых в оборот денег; 5) инструментарий, обеспечивающий регулирование денежного оборота.

Денежная единица - это законодательно утвержденный денежный знак, который применяется для соизмерения цен всех товаров. Как правило, денежная единица состоит из мелких пропорциональных частей. В большин- 
стве государств функционирует десятичная система, например, 1 российский рубль делится на 100 копеек, 1 евро делится на 100 евроцентов, даже современный английский фунт стерлингов содержит 100 пенсов, хотя ранее долгое время делился на 20 шиллингов.

Денежные знаки - это представители денег в виде металлических монет или бумажных купюр, изготовленные по установленным законом образцам специализированными государственными организациями. Они признаются государством в качестве единственного законного платежного средства с принудительным по отношению к деньгам в собственном смысле слова курсом, выраженным в национальной денежной единице. В настоящее время в России денежные знаки представлены в виде бумажных купюр и разменной монеты.

Основными разновидностями денежных знаков являются кредитные знаки или банкноты, бумажные деньги (государственные казначейские билеты), а также разменная монета, они считаются законными платежными средствами во всех странах. Банкнота, или кредитный знак, или банковский билет - это денежный знак, выпускаемый в обращение и гарантируемый центральным банком (рис. 1).

В настоящее время на территории нашей страны билеты Банка России являются единственным законным средством платежа наряду с монетой. Их подделка и/или противоправное изготовление преследуются по закону. Банкноты и выпускаемая для их размена монета признаются безусловными обязательствами Центрального банка РФ и обеспечиваются всеми его активами. Образно выражаясь, банкнота - это билет на все, что про- дается и покупается за деньги, важно, чтобы сумма денег, представленная этими билетами, точно совпадала с ценой.

Банкноты изготавливают из небольших прямоугольных листков бумаги на строго охраняемых государственных фабриках, с точки зрения финансов банкноты выпускает центральный банк. Например, в СССР с 1924 по 1994 г. бумажные денежные знаки достоинством до 10 рублей выпускались Казначейством и назывались государственными казначейскими билетами, а выше 10 рублей выпускались Государственным банком СССР и назывались билетами Государственного банка СССР (см. рис. 2).

В Российской Федерации решения о выпуске в обращение новых банкнот и монет, изъятии из обращения старых, определении номиналов и установлении образцов новых банкнот и монет принимаются Советом директоров Банка России. Описания новых денежных знаков, как монет, так и банкнот, обязательно широко публикуются. Ветхие и поврежденные банкноты обмениваются Банком России без ограничений, при условии, что 55 \% и более от площади банкноты имеется в наличии. В 2017 г. в России обращаются банкноты достоинством в $10,50,100,200,500$, $1000,2000,5000$ рублей.

\section{Банкнота как особая}

\section{предъявительская ценная бумага}

Современные банкноты воспринимаются всеми участниками оборота не иначе как сами деньги, но так было не всегда. В России государственные ассигнации 1769 г. стали первы-

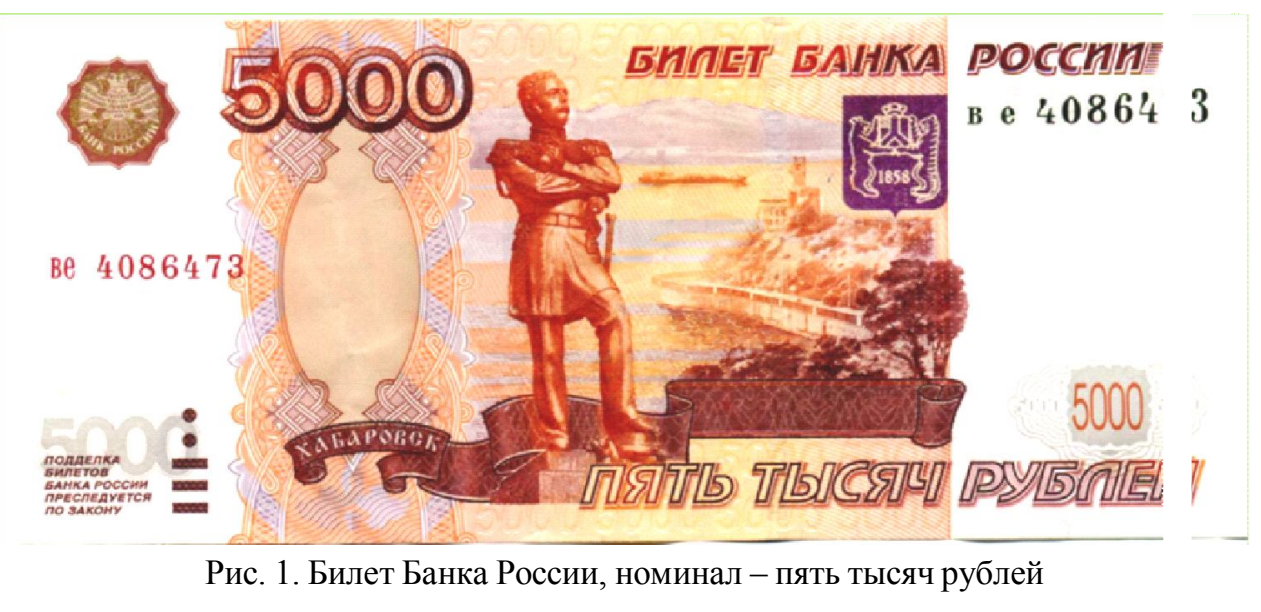


ми ценными бумагами на предъявителя. В Манифесте от 29 декабря 1768 г. повелевалось, что «если отпущенные государственные ассигнации будут обратно приносимы частными людьми в банк для получения за них денег, то банк тот повинен прилагать крайнее старание, чтобы не задерживать того приносителя ни мало; но, приняв от него, сколько он принес ассигнаций, должен отдать немедленно написанное в них число денег, не делая никаких определений и не токмо не требуя расписки, но и не спрашивая, кто он таков, откуда получил ассигнацию, а только подлежит записывать в книге прием ассигнаций и выдачу денег» [1].

Большинство ценных бумаг предоставляют возможности для вложений денежного капитала с целью его приращения, в то же время они являются инструментами финансирования инвестиций. Выпуская ценные бу- маги, юридические лица привлекают денежные средства для развития своей предпринимательской деятельности. Для приобретателей ценные бумаги являются прежде всего средством получения дохода, как правило, без активного личного участия, без труда в самой организации.

Внешне процесс финансирования инвестиций путем выпуска ценных бумаг вполне аналогичен движению банковского кредитного капитала. Фактически и при продаже ценных бумаг для их эмитента, и при зачислении заемщику суммы кредита от банка денежные средства превращаются в производительный капитал на определенных условиях. При предоставлении кредита банком поставщик капитала (банк-кредитор) и потребитель капитала (заемщик) вступают между собой в финансово-экономические, гражданско-правовые

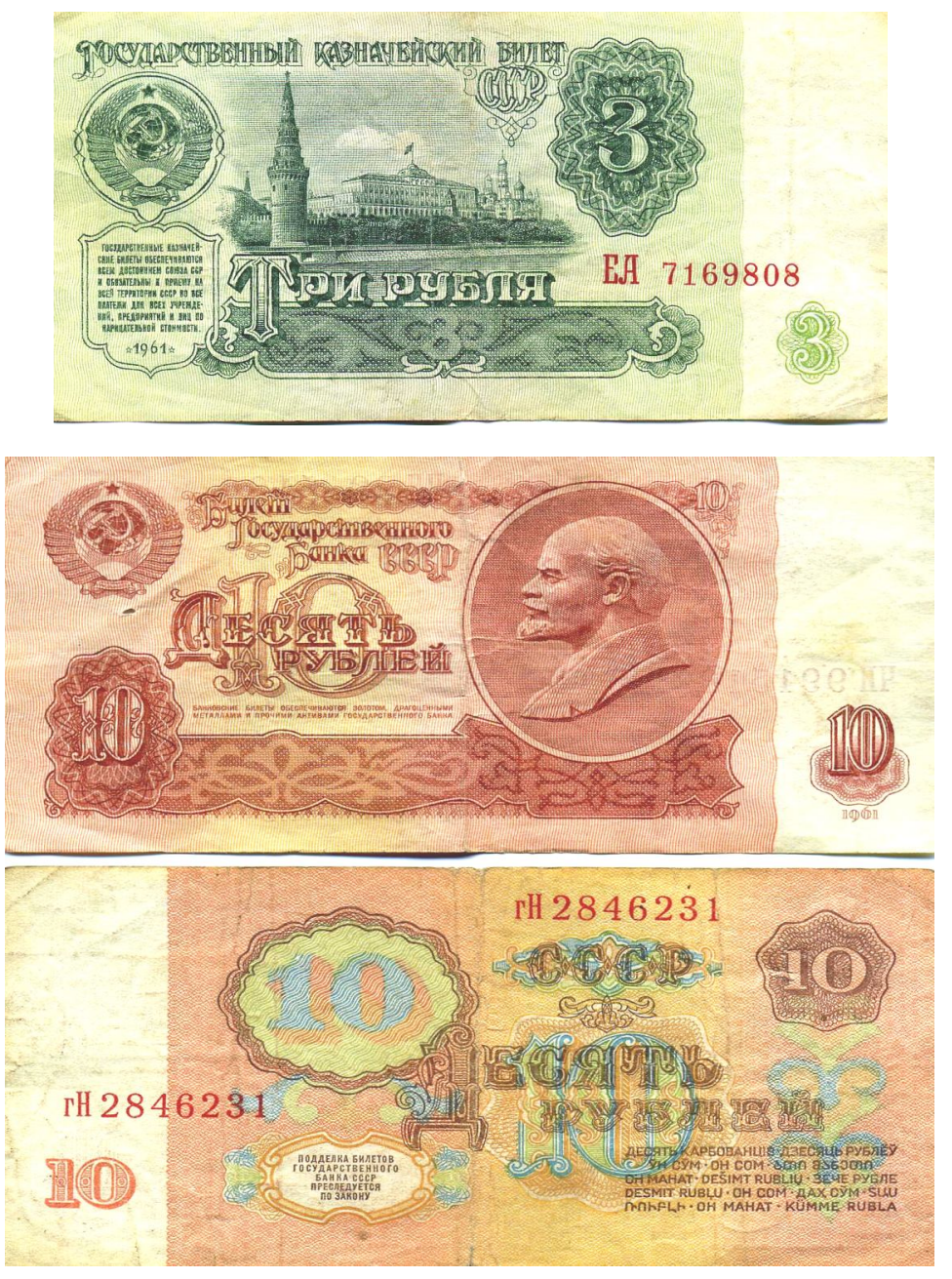

Рис. 2. Государственный казначейский билет СССР, номинал - три рубля. Билет Государственного Банка СССР, номинал - десять рублей 
отношения, которые регламентируются в кредитном договоре. Экономический смысл этих отношений заключается в том, что заемщик в установленный кредитным договором срок обязуется возвратить полученную в долг сумму денег, а также сверх этого заплатить за пользование капиталом определенную плату процент за кредит, который является ценой банковского кредитного капитала как товара.

При приобретении ценных бумаг поставщик капитала (инвестор) и потребитель капитала (эмитент ценных бумаг) также вступают между собой в финансово-экономические, гражданско-правовые отношения, которые регламентируются условиями выпуска конкретных ценных бумаг. Носителями этих условий являются сами ценные бумаги. Это их свойство позволяет экономике сделать гигантский скачок вперед, ведь если бы ценные бумаги на все время до окончания срока использования капитала оставались у инвестора, то ситуация была бы тождественна банковскому кредитованию. Однако главная ценность бумаг состоит в том, что они предоставляют инвесторам возможность участия в особых, более активных и разнообразных отношениях и операциях, которые основаны на условиях и содержании ценных бумаг. Если при движении банковского кредитного капитала предметом отношений кредитора и заемщика является та или иная сумма денежного капитала, то отношения инвестора и организации, выпускающей ценные бумаги, строятся именно на самих ценных бумагах. При этом потребитель капитала (эмитент ценных бумаг) выступает продавцом ценной бумаги, а поставщик капитала (инвестор) становится ее покупателем.

Инвестор (держатель) ценной бумаги согласно условиям выпуска ценных бумаг может легко и быстро передавать свое право собственности другому лицу путем продажи ценной бумаги или ее отчуждения каким-либо иным способом. В результате ценные бумаги становятся объектами многократной купли-продажи с целью получения дохода от этих сделок, а следовательно, обладают свойствами высоколиквидного непотребляемого товара.

С финансово-экономических позиций за каждой ценной бумагой существует капитал, а именно вложенные в производительных, по- лезных целях денежные средства, работающие в рамках какой-то предпринимательской либо общественно-полезной деятельности. Продавая ценную бумагу, предыдущий владелец тем самым предоставляет возможность новому владельцу ценной бумаги занять его место инвестора в этом финансово-экономическом, предпринимательском отношении. Уступая свое место инвестора, продавец ценной бумаги не несет никакой ответственности за качество данного «товара», поскольку за весь срок владения ценной бумагой он никак не мог изменить его. Качество этого специфического товара неизменно и скрепляется условиями, которые гарантирует эмитент, выпускающий ценную бумагу.

Место в финансово-экономическом, предпринимательском отношении, оформленном ценной бумагой, новый инвестор-приобретатель занимает в полном объеме, точно соответствующем тому объему прав, который предоставлялся ценной бумагой предыдущему инвестору. Однако с течением времени происходит поступательное развитие эмитента иенной бумаги, в процессе своей деятельности он растет. Его возможности обеспечивать прирост вкладываемого в его деятельность и имущество денежного капитала увеличиваются, что закономерно влечет удорожание указанного места для инвестора. Поэтому в долгосрочном периоде, от года и более, цена, по которой ценная бумага продается, растет. Следовательно, большинство инвесторов покупают ценные бумаги для того, чтобы через некоторое время их продать дороже иены приобретения. В результате ценные бумаги обращаются (покупаются и продаются) под влиянием потребности инвесторов получить приращение своего денежного капитала на том экономическом основании, что существуют реальные, успешно работающие эмитенты либо пользующиеся спросом товары и имущество. Следовательно, ценная бумага - это юридический инструмент получения дохода в результате экономического роста эмитента, удорожания товара или имущества, виртуального актива, которые представлены данной ценной бумагой.

Совершенно иное и особое положение занимает в ряду ценных бумаг банкнота. С одной стороны, это классическая ценная бума- 
га на предъявителя, обладающая пятью известными признаками: 1) удостоверяет права ее собственника; 2) для реализации прав обязательно предъявляется; 3) обладает публичной достоверностью; 4) существует на законном основании; 5) используется для оборота. С другой стороны, банкнота не является инструментом инвестиций и юридическим инструментом получения дохода в результате экономического роста эмитента. Лицо становится держателем банкнот в процессе публично-правовых, гражданско-правовых, предпринимательских, трудовых, семейных, процессуальных отношений в результате расчета по каким-то публичным обязанностям или частноправовым денежным обязательствам. Став владельцем банкнот, это лицо может использовать их опять и только для расчетов.

Особо следует подчеркнуть, что в отличие от иных ценных бумаг рыночной цены (биржевого курса) банкноты не существует, поэтому банкнота не растет и не падает, ее номинал неизменен. Наоборот, как было отмечено выше, с течением времени на одну и ту же банкноту, во всяком случае в Российской Федерации за период с 1998 по 2017 г., можно получить (купить) все меньше товаров (работ, услуг, имущественных прав). Наряду с этим специфика банкноты как ценной бумаги еще и в том, что для ее введения в оборот и для изъятия из оборота обязательно участие государства в лице своего центрального банка.

\section{Результаты}

Банкнота или банковский билет, как денежный знак, выпускаемый в обращение и гарантируемый центральным банком, позволяет рационально и быстро производить колоссальную массу наличных расчетов в экономике. Любое лицо становится держателем банкнот в результате расчета по каким-то публичным обязанностям или частноправовым денежным обязательствам. С течением времени на одну и ту же банкноту можно получить (купить) товаров, работ, услуг, имущественных прав меньше, чем год и более назад. Государство в лице центрального банка страны обязательно участвует и полностью определяет судьбу банкноты как предъявительской ценной бумаги, носителем условий ее обращения является она сама. Банкнота занимает в ряду ценных бумаг глубоко специфичное положение.

\section{Выводы}

Деньги в форме листков бумаги (бумажные деньги) появились в связи с затруднением металлического денежного обращения и начали функционировать как заместители серебряных и золотых монет. В настоящее время бумажные деньги, банкноты не обмениваются на золото. В Российской империи бумажные деньги начали применяться с 1769 года. Банкноты в Российской Федерации выпускает (эмитирует) Банк России. Инфляционный процесс обусловливает непрерывное обесценивание обращающихся банкнот.

Ценные бумаги предоставляют возможности для вложений денежного капитала с целью его приращения, в то же время они являются инструментами финансирования инвестиций. Банкнота, будучи платежным средством, не является инвестиционным инструментом и юридическим средством получения дохода в результате экономического роста эмитента. Лицо становится держателем банкнот в результате расчета по каким-то публичным обязанностям или частноправовым денежным обязательствам. За банкнотой всей своей гарантийной, обеспечительной и принудительной мощью стоит государство.

\section{СПИСОК ЛИТЕРАТУРЫ}

1. О учреждении в Санкт-Петербурге и Москве Государственных банков для вымена ассигнаций // Манифест Екатерины II от 29 дек. 1768 г. - Электрон. текстовые дан. - Режим доступа: http:/нэб.pф/ catalog/000200_000018_RU_NLR_DIGIT_69672/ viewer/. - Загл. с экрана.

\section{REFERENCES}

1. O uchrezhdenii v Sankt-Peterburge i Moskve Gosudarstvennykh bankov dlya vymena assignatsiy [On Foundation of State Banks to Exchange Tickets in Saint Petersburg and Moscow]. Manifest Ekateriny II ot 29 dek. $1768 \mathrm{~g}$. [Catherine II Manifesto of December 29, 1768]. URL: http://нэб.pф/catalog/000200_000018_ RU_NLR_DIGIT_69672/viewer/. 


\section{ВОПРОСЫ ЧАСТНОПРАВОВОГО РЕГУЛИРОВАНИЯ}

\section{Information about the Author}

Alexander I. Goncharov, Doctor of Juridical Sciences, Doctor of Economic Sciences, Professor, Department of Civil Law Disciplines, Volgograd Institute of Management - RANEPA Branch, Gagarina St., 8, 400131 Volgograd, Russian Federation, goncharova.sofia@gmail.com.

\section{Информация об авторе}

Александр Иванович Гончаров, доктор юридических наук, доктор экономических наук, профессор кафедры гражданско-правовых дисциплин, Волгоградский институт управления - филиал РАНХиГС, ул. Гагарина, 8, 400131 г. Волгоград, Российская Федерация, goncharova.sofia@gmail.com. 